\title{
Biphasic Activation of the mTOR Pathway in the Gustatory Cortex Is Correlated with and Necessary for Taste Learning
}

\author{
Katya Belelovsky, Hanoch Kaphzan, Alina Elkobi, and Kobi Rosenblum \\ Department of Neurobiology and Ethology, Faculty for Science, University of Haifa, Haifa 30905, Israel
}

Different forms of memories and synaptic plasticity require synthesis of new proteins at the time of acquisition or immediately after. We are interested in the role of translation regulation in the cortex, the brain structure assumed to store long-term memories. The mammalian target of rapamycin, mTOR (also known as FRAP and RAFT-1), is part of a key signal transduction mechanism known to regulate translation of specific subset of mRNAs and to affect learning and synaptic plasticity. We report here that novel taste learning induces two waves of mTOR activation in the gustatory cortex. Interestingly, the first wave can be identified both in synaptoneurosomal and cellular fractions, whereas the second wave is detected in the cellular fraction but not in the synaptic one. Inhibition of mTOR, specifically in the gustatory cortex, has two effects. First, biochemically, it modulates several known downstream proteins that control translation and reduces the expression of postsynaptic density-95 in vivo. Second, behaviorally, it attenuates long-term taste memory. The results suggest that the mTOR pathway in the cortex modulates both translation factor activity and protein expression, to enable normal taste memory consolidation.

\section{Introduction}

Long-term taste memory, in a similar way to other memories, is assumed to be stored at least partially in the cortex (Bures et al., 1998; Rosenblum, 2008). Different forms of learning and synaptic plasticity, including taste memory consolidation in the gustatory cortex (GC), are sensitive to general protein synthesis inhibition during or immediately after learning (Rosenblum et al., 1993; Meiri and Rosenblum, 1998). However, the molecular mechanism that regulates neuronal translation and memory consolidation processes in the cortex is not clear. Correlative studies identify different post-translational modifications in the GC after novel taste learning (Berman et al., 1998; Belelovsky et al., 2005; Merhav et al., 2006; Yefet et al., 2006). Specifically, some of these correlative events between protein phosphorylation in the GC and taste learning are known to affect and modulate the function of the translation machinery (Belelovsky et al., 2005). In addition, the involvement of different translation initiation factors, including eIF2 $\alpha, 4 \mathrm{E}-\mathrm{BP} 2$, and $\mathrm{S} 6 \mathrm{~K}$, in taste learning was reported in transgenic mice studies (Banko et al., 2007; Costa-Mattioli et al., 2007; Antion et al., 2008).

Some of the correlative modifications, observed after novel taste or conditioned taste aversion (CTA) learning, are detected in proteins that are either direct or indirect targets of the mammalian target of rapamycin (mTOR). The mTOR pathway can be activated by a number of growth factors and nutrients, resulting in increased phosphorylation of mTOR on residue Ser2448 (Hay

Received July 2, 2008; revised Nov. 12, 2008; accepted Jan. 9, 2009.

This work was supported by an Israel Science Foundation grant to K.R. We thank Dr. Paul Skehel for constructive comments on this manuscript.

Correspondence should be addressed to Dr. Kobi Rosenblum, Department of Neurobiology and Ethology, University of Haifa, Haifa 31905, Israel. E-mail: kobir@psy.haifa.ac.il.

DOI:10.1523/JNEUROSCI.3809-08.2009

Copyright $\odot 2009$ Society for Neuroscience $\quad$ 0270-6474/09/297424-08\$15.00/0 and Sonenberg, 2004). Two structurally and functionally distinct TOR complexes, TORC1 and TORC2, exist. TORC1 mediates rapamycin-sensitive, TOR-shared signaling to the translation machinery, the transcription apparatus, and other targets. TORC2 mediates rapamycin-insensitive, TOR2-unique signaling to the actin cytoskeleton (Loewith et al., 2002). The inhibition of mTOR by rapamycin interferes with the translation of specific subpopulations of mRNAs, an action which significantly distinguishes the action of rapamycin from other general protein synthesis inhibitors, such as anisomycin or cycloheximide (Raught et al., 2001). The downstream targets of mTOR are all components of translation machinery, including ribosomal protein kinase (S6K1) and elongation factors $1 \mathrm{~A}$ and 2 (eEF1A and eEF2). These proteins are mostly involved in ribosome recruitment to mRNA, and they regulate both the initiation and elongation phases of translation (Hay and Sonenberg, 2004).

The significant role of the mTOR pathway in different forms of synaptic plasticity has been pointed out in several studies (Casadio et al., 1999; Tang et al., 2002; Cammalleri et al., 2003; Horwood et al., 2006; Tsokas et al., 2007). Rapamycin application prevented long-term facilitation in Aplysia (Casadio et al., 1999) and blocked high-frequency and BDNF-induced long-term potentiation in the rat hippocampus (Tang et al., 2002). Furthermore, mTOR-dependent activation of dendritic S6K1 was shown to be necessary for the induction phase of protein synthesisdependent synaptic plasticity (Cammalleri et al., 2003). However, only few studies have investigated the role of mTOR signaling in learning and memory formation, focusing mainly on hippocampus and amygdala-dependent forms of learning (Tischmeyer et al., 2003; Dash et al., 2006; Parsons et al., 2006; Bekinschtein et al., 2007).

In the current study, we sought to determine the role of mTOR signaling in the GC after novel taste learning in the rat. To 
establish this, we examined the effect of rapamycin microinfusions to the GC before and after taste learning. Next, we assessed the temporal pattern of mTOR pathway activation at several time points after taste learning. Moreover, we characterized the effect of rapamycin application on total and phospho-levels of several translation regulators, affecting both the initiation and elongation phases. Finally, we addressed the relationship between mTOR-dependent translation control and the expression levels of postsynaptic protein postsynaptic density-95 (PSD-95) that is known to stabilize synaptic plasticity (Ehrlich et al., 2007) and which induced expression in the GC is necessary for taste memory consolidation (Elkobi et al., 2008).

\section{Materials and Methods \\ Subjects}

Adult male Wistar rats, weighing 200-250 g (Harlan), were maintained on a $12 \mathrm{~h}$ light/dark cycle. The procedures were performed in strict accordance with the University of Haifa regulations and the US National Institutes of Health (NIH) guidelines (NIH publication number 8023).

\section{Behavioral procedures}

Conditioned taste aversion and latent inhibition. CTA was performed as described previously (Rosenblum et al., 1993). Saccharin $(0.1 \% \mathrm{w} / \mathrm{v}$, sodium salt) or $\mathrm{NaCl}(0.3 \%)$ were used as the unfamiliar taste in training [i.e., the conditioned stimulus (CS)] and injection of $\mathrm{LiCl}(0.15 \mathrm{~m}, 2 \%$ body weight, i.p.) as the malaise-inducing agent [unconditioned stimulus (UCS)]. At the beginning of the behavioral experiment, the rats were trained for $3 \mathrm{~d}$ to get their daily water ratio once a day for $15 \mathrm{~min}$ from two pipettes, each containing $10 \mathrm{ml}$ of water. On the conditioning day, they were allowed to drink the saccharin solution instead of water from similar pipettes for $15 \mathrm{~min}$, and $50 \mathrm{~min}$ later they were injected with $\mathrm{LiCl}$. Under these conditions, $2 \mathrm{~d}$ after training the conditioned rats preferred water to saccharin in a multiple choice test situation (three pipettes with $5 \mathrm{ml}$ of saccharin each and three with $5 \mathrm{ml}$ of water each), whereas nonconditioned rats preferred saccharin to water. The behavioral data are presented in terms of aversion index, defined as [ml water/( $\mathrm{ml}$ water plus ml saccharin)] consumed in the test; 0.5 is a chance level, and the higher the aversion index, the more the rats prefer water to the conditioned taste.

In some experiments, a latent inhibition (LI) procedure (Lubow, 1989) was combined with CTA to further isolate the effect of taste learning from the potential confounding effects of the UCS and the CS-UCS association. Latent inhibition is a process by which pre-exposure to a sensory stimulus diminishes the ability of that same stimulus to serve as an associated stimulus in subsequent learning. Thus, exposure of rats to an unfamiliar taste several days before this same taste serves as the CS in CTA training and significantly reduces the acquired aversion (Rosenblum et al., 1993). Under such conditions, the degree of aversion after CTA training is a measure of the memory for saccharin acquired incidentally (Hebb, 1949) in the pre-CTA trial. In LI experiments, the rats were exposed to two $10 \mathrm{ml}$ pipettes of saccharin for $15 \mathrm{~min}, 2 \mathrm{~d}$ before CTA training, as described above, in which saccharin was used as the CS. Testing was also as described above for the usual CTA procedure.

Incidental taste learning. Two groups of rats were water deprived for $24 \mathrm{~h}$ and then pretrained for $3 \mathrm{~d}$ to get their daily water ration once a day for $15 \mathrm{~min}$ from two pipettes each containing $10 \mathrm{ml}$ of water. On the fourth day, the experimental group was exposed for $15 \mathrm{~min}$ to unfamiliar taste (saccharin $0.1 \%$ or $\mathrm{NaCl} 0.3 \%$ ), whereas the control group was exposed for the same time period to water (Rosenblum et al., 1993; Berman et al., 1998).

\section{Microsurgery and microinfusion}

Microinfusions into the gustatory cortex were performed via chronically implanted cannulae. Rats were anesthetized with equithesine $(0.45 \mathrm{ml} /$ $100 \mathrm{~g} ; 2.12 \% \mathrm{w} / \mathrm{v} \mathrm{MgSO}_{4}, 10 \% \mathrm{v} / \mathrm{v}$ ethanol, $39.1 \% \mathrm{v} / \mathrm{v}$ 1,2,-propranolol, $0.98 \% \mathrm{w} / \mathrm{v}$ sodium pentobarbital, and $4.2 \% \mathrm{w} / \mathrm{v}$ chloral hydrate), restrained in a stereotactic apparatus (Stoelting), and implanted bilaterally with a 10 -mm-guide stainless cannula (23 gauge) aimed at the rat gusta- tory cortex (anteroposterior, $+1.2 \mathrm{~mm}$ relative to bregma; lateral, \pm 5.5 $\mathrm{mm}$; ventral, $-5.5 \mathrm{~mm}$ ) (Paxinos and Watson, 1986). The cannulae were positioned in place with acrylic dental cement and secured by two skull screws. A stylus was placed in the guide cannula to prevent clogging. After the microsurgery, animals were injected intramuscularly with antibiotic and were allowed to recuperate for 1 week.

For microinfusion, the stylus was removed from the guide cannula, and a 28 gauge injection cannula, extending $1.0 \mathrm{~mm}$ from the tip of the guide cannula, was inserted. The injection cannula was connected via PE20 tubing to a Hamilton microsyringe driven by a microinfusion pump (CMA/100; Carnegie Medicin). Microinfusion was performed bilaterally in a $1.0 \mu \mathrm{l}$ volume per hemisphere delivered over $1 \mathrm{~min}$. The injection cannula was left in position before withdrawal for an additional 1 min to minimize dragging of the injected liquid along the injection tract.

For the behavioral set of experiments, the rats were injected bilaterally either with rapamycin (10 $\mu \mathrm{M}$; Sigma) or with vehicle $(0.2 \%$ DMSO in saline), $25 \mathrm{~min}$ before or $100 \mathrm{~min}$ after the pre-exposure in the LI paradigm. For the biochemical part, to provide a within-subject control, rapamycin and vehicle or U-0126 and vehicle were injected to each GC of the same animal. To avoid lateral bias, animals were injected interchangeably between both sides.

The rats were decapitated $15 \mathrm{~min}$ or $45 \mathrm{~min}$ after the microinjection with rapamycin and $20 \mathrm{~min}$ after the microinjection with U-0126, and the gustatory cortices were subjected to Western blot analysis.

\section{Hippocampal slice preparation}

After decapitation, the brain was immediately immersed in cold $\left(4^{\circ} \mathrm{C}\right)$ carboxygenated $\left(95 \% \mathrm{O}_{2}, 5 \% \mathrm{CO}_{2}\right)$ artificial CSF [aCSF (in mM): 124 $\mathrm{NaCl}, 5 \mathrm{KCl}, 1.2 \mathrm{MgSO}_{4} 1.2 \mathrm{NaH}_{2} \mathrm{PO}_{4}, 26 \mathrm{NaHCO}_{3}, 10$ D-glucose, 2.4 $\mathrm{CaCl}$, and after $\sim 120 \mathrm{~s}$, both hippocampi were dissected out in a plate filled with cold $\left(4^{\circ} \mathrm{C}\right) \mathrm{aCSF}$ on ice. The hippocampi were put on a cooled stand of a McIlwain tissue chopper TC752 (Campden Instruments), cut into $400 \mu \mathrm{m}$ slices, and then put back into a chamber filled with carboxygenated cold $\left(4^{\circ} \mathrm{C}\right)$ aCSF.

The slices were transferred to a holding chamber for $\sim 20-30 \mathrm{~min}$, to reach room temperature, and were then transferred to a six-chamber pharmacological instrument, designed to our specifications by Scientific Systems Design Company. All of the slices tested in any one experiment (i.e., in all six chambers) were produced by the same procedure from the same rat.

The hippocampal slices were heated to $32^{\circ} \mathrm{C}$ and were kept in the chamber for $5 \mathrm{~h}$ before any pharmacological intervention. Each chamber contained four slices. The slices were perfused with heated and carboxygenated aCSF via a model MP3 peristaltic pump (Gilson), at a rate of $\sim 2$ $\mathrm{ml} / \mathrm{min}$. The chamber space was carboxygenated and humidified. The chamber was an interface type, and the slices were placed on a lens paper. The slices were analyzed occasionally for their viability using extracellular recordings of field EPSP in the CA1 region.

After insulin application ( $10 \mathrm{~min} ; 1.5 \mu \mathrm{M}) /$ control condition, the slices were removed from the pharmacological chamber and snap frozen on dry ice. After freezing, slices were homogenized in SDS sample buffer as described previously (Rosenblum et al., 1997). Four slices from each chamber were combined as two pairs, and the two slices of each pair were homogenized as a single sample, so that each chamber yielded two samples.

\section{Sample preparation and Western blotting}

Preparation of total sample. At different time points after the incidental taste learning $(0,15,30$, and $180 \mathrm{~min})$ and after the microinfusion in the pharmacological experiments ( 15 and $45 \mathrm{~min}$ ), the rats were decapitated, the brain was removed, and the gustatory cortices were dissected out. Each GC was homogenized in $300 \mu$ lice-cold lysis buffer in a glass-Teflon homogenizer. The lysis buffer was composed of the following (in $\mathrm{mM}$, unless indicated otherwise): 10 HEPES, 2 EDTA, 2 EGTA, 5 Na fluoride, 0.5 DTT, $0.1 \mathrm{Na}$ orthovanadate, 0.1 phenylmethylsulfonyl fluoride, 10 $\mu \mathrm{g} / \mathrm{ml}$ leupeptin, $10 \mu \mathrm{g} / \mathrm{ml}$ aprotin, and $1 \%$ phosphatase inhibitor mixture 1 (Sigma). Protein content was determined by Bradford assay (Bio$\mathrm{Rad})$. Appropriate volumes of $2 \times$ SDS sample buffer were added to the homogenates, and samples were boiled for $5 \mathrm{~min}$ and stored at $-20^{\circ} \mathrm{C}$.

Preparation of synaptoneurosomal fraction. The protocol was adopted from Quinlan et al. (1999) and is similar to the protocol used in Kelleher 
et al. (2004). In brief, fresh cortex was homogenized in a glass/glass $5 \mathrm{ml}$ tissue grinder in $1 \mathrm{ml}$ of lysis buffer (as detailed above). An aliquot of the homogenized tissue $(100 \mu \mathrm{l})$ was retained, and after determination of protein amount, it was mixed with appropriate volume of $2 \times$ SDS sample buffer (total fraction). The remaining material was passed once through a $100 \mu \mathrm{m}$ filter and once through a $5 \mu \mathrm{m}$ filter (Millipore Bioscience Research Reagents), attached to a $5 \mathrm{ml}$ syringe. The homogenized tissue was centrifuged at $1000 \times g$ for $10 \mathrm{~min}$ at $4^{\circ} \mathrm{C}$. The pellet contained the synaptoneurosome fraction, whereas nonspecific material remained in the supernatant. Lysis buffer $(100 \mu \mathrm{l})$ was added to the pellet, the protein amount of both the pellet and supernatant fractions was determined, and $2 \times$ SDS sample buffer was added at appropriate volume to both; the samples were boiled for $5 \mathrm{~min}$ and stored at $-20^{\circ} \mathrm{C}$.

Western blotting. Samples ( $8-15 \mu \mathrm{g}$ of protein per well) were loaded on $7.5 \%$ or $10 \%$ SDS-PAGE gels and resolved by standard electrophoresis. The gels were transferred electrophoretically onto nitrocellulose membranes (pore size, $0.45 \mu \mathrm{m}$; Invitrogen). Membranes were blocked for $1 \mathrm{~h}$ at room temperature with blocking buffer [3\% BSA in TBS containing $0.1 \%$ Tween 20 (TBS-T)] and probed overnight at $4^{\circ} \mathrm{C}$ using primary antibodies for $\mathrm{p} 44 / 42$ mitogen-activated protein (MAP) kinase [extracellular signal-regulated protein kinase (ERK)], 1:1000; phospho- p44/42 MAP kinase (p-ERK), 1:1000; p70 S6 kinase (S6K1), 1:500; phospho(Thr389)p70 S6 kinase (p-S6K1), 1:750; mTOR, 1:500 and phosphomTOR (p-mTOR), 1:1000; eEF2, 1:1000 and phospho-eEF2 (p-eEF2), 1:1000, all rabbit polyclonal and all from Cell Signaling Technology. eEF1A, 1:1000, mouse monoclonal was from Upstate Biotechnology, and $\beta$-actin, 1:3000, goat polyclonal, was purchased from Santa Cruz. After washing in TBS-T (three washes, $10 \mathrm{~min}$ each), the membranes were incubated with goat anti-rabbit (IgG), goat anti-mouse (IgG), or donkey anti-goat (IgG) horseradish peroxidase-conjugated (all from Jackson ImmunoResearch), and proteins were visualized using chemiluminescence (ECL and ECL plus Western blotting analysis system; GE Healthcare).

Quantification was performed with a charge-coupled device camera (XRS; Bio-Rad). Each sample was measured relative to the background, and phosphorylation levels were calculated as the ratios between the results from the antibody directed against the phospho-proteins and those from the antibody directed against the phosphorylation stateindependent forms of the proteins; a ratio of unity would indicate that there was no difference in protein phosphorylation. The results are expressed as means \pm SEM. For statistical analysis, we used the paired $t$ test, $t$ test assuming equal variances, the univariate ANOVA test, and repeated-measures ANOVA test. For post hoc analysis, we used Tukey honestly significant differences test.

\section{Results}

Novel taste learning induces the activation of mTOR pathway in the GC

To examine the effect of novel taste (saccharin) drinking on the expression of mTOR pathway, we collected the GC of rats at several time points after the taste learning. Our results indicate that incidental taste learning results in two waves of mTOR phosphorylation on Ser2448, the site known to be critical for mTOR activation (Raught et al., 2001). No change in mTOR phosphorylation was observed immediately after the exposure to novel taste; however, within $15 \mathrm{~min}$, it increased by $21 \%$ ( $t$ test, $t_{(14)}=$ $-2.43 ; p<0.03)$. Thirty minutes after the learning, the levels of phospho-mTOR returned to the baseline and remained unchanged at the time point of $90 \mathrm{~min}$ after learning. With the passage of $180 \mathrm{~min}$, we detected a second wave of mTOR activation of $27 \%\left(t\right.$ test, $\left.t_{(15)}=-2.93 ; p<0.01\right)$ (Fig. $\left.1 A\right)$.

Next, we analyzed the phosphorylation levels of S6K1 at same time points studied for mTOR. Again, we observed a two-wave pattern of S6K1 phosphorylation, increasing $15 \mathrm{~min}(29 \%)$ and $180 \mathrm{~min}(22 \%)$ after the taste learning $\left(t\right.$ test, $t_{(8)}=-2.55 ; p<$ 0.05 and $t_{(15)}=-2.45 ; p<0.03$, respectively) (Fig. $1 B$ ).

Because S6K1 is a known substrate of mTOR, we examined
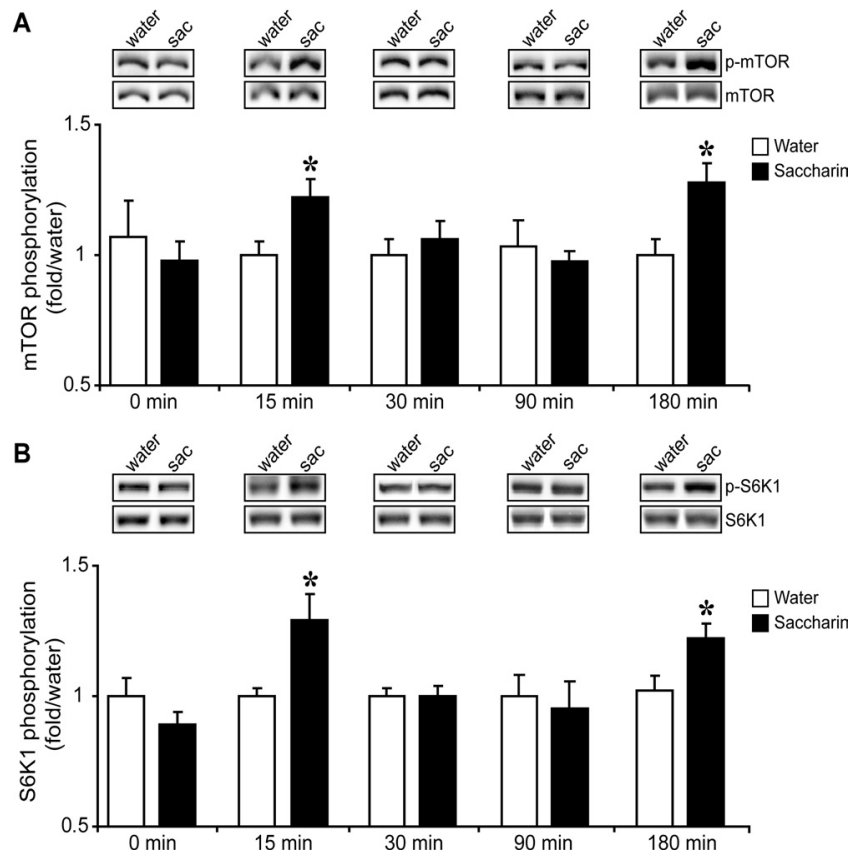

Figure 1. mTOR and S6K1 are phosphorylated in the gustatory cortex in a biphasic manner. A protein phosphorylation is expressed as the ratio between saccharin and water values. $\boldsymbol{A}$, mTOR phosphorylation is increased 15 and 180 min after novel taste $(n=8, p<0.03 ; n=9$, $p<0.01$, respectively). Here and in other figures, error bars are SEM, whereas asterisk represents a significant change. The top panel depicts representative immunoblots of anti-protein antibody and anti-phospho-specific antibody (Ser2448) from the gustatory cortex 0, 15, 30, 90, and 180 min after novel taste saccharin (sac) or familiar taste (water). $\boldsymbol{B}$, S6K1 phosphorylation is also increased within 15 and 180 min of novel taste drinking $(n=5, p<0.05 ; n=8, p<$ 0.03 , respectively). The top panel depicts representative immunoblots of anti-protein antibody and phospho-specific antibody (Thr389) from the gustatory cortex for all time points.

the correlation between mTOR and S6K1 activation. Indeed, we found that a significant positive correlation exists between the two phosphorylation events in the GC after novel taste learning (Spearman's $r=0.341 ; p<0.02$; data not presented).

\section{S6K1 phosphorylation is increased in synaptoneurosomal fraction $15 \mathrm{~min}$ but not $180 \mathrm{~min}$ after novel taste}

After the observation that S6K1 phosphorylation is correlated with taste learning in the gustatory cortex, we analyzed S6K1 phosphorylation in a synaptoneurosomal fraction made from gustatory cortex. First, we confirmed the enrichment of the synaptic protein PSD-95 compared with total fraction $\left(t\right.$ test, $t_{(8)}=$ $-7.21 ; p<0.001$ ) (Fig. $2 B$ ). The levels of $\beta$-actin were comparable in both fractions [not significant (n.s.)]. Next, we analyzed the total and phospho-levels of S6K1 in the synaptic and total fractions. Surprisingly, the total expression of S6K1, calculated as a ratio between $\mathrm{S} 6 \mathrm{~K} 1$ and $\beta$-actin levels, was significantly reduced in synaptoneurosomes, compared with total fraction ( $t$ test, $t_{(11)}$ $=4.5 ; p<0.001)($ Fig. $2 A, B)$, proposing a decreased S6K1 expression in the synapse. The analysis of $S 6 \mathrm{~K} 1$ phosphorylation revealed no difference between the fractions (Fig. 2 B). However, the ratio between phospho- and total S6K1, which indicates activated S6K1 levels, was significantly increased $\left(t\right.$ test, $t_{(11)}=-2.22$; $p<0.05$ ) (Fig. 2A).

We next evaluated S6K1 total and phospho-levels in synaptoneurosomes after novel taste. We focused on the two time-points, where phospho-S6K1 was increased in the total lysate: 15 and 180 min. Here, we obtained a differential effect of activation: at the first point, p-S6K1 was increased $\left(t\right.$ test, $\left.t_{(7)}=-2.7 ; p<0.03\right)$, 

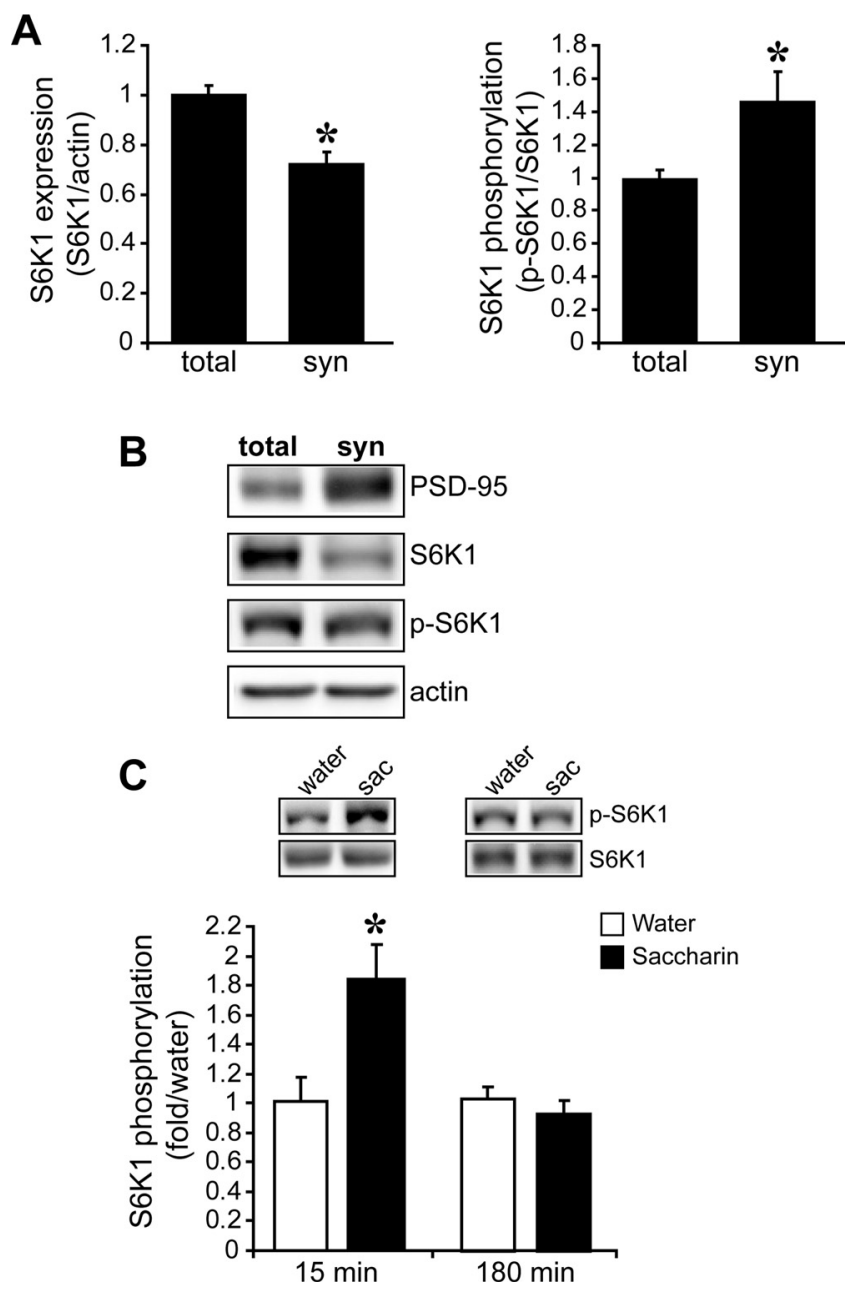

Figure 2. Differential temporal activation of $56 \mathrm{~K} 1$ in the synaptoneurosomes made from $\mathrm{GC}$. $\boldsymbol{A}, \boldsymbol{B}$, The levels of PSD-95 and total and phospho-S6K1 were examined by immunoblotting in the synaptoneurosomal fraction (syn) and compared with the level in the initial lysate (total). The levels of postsynaptic marker PSD-95 are significantly increased in the synaptic fraction $(n=5 ; p<0.001)$. $56 \mathrm{~K} 1$ level in the synaptoneurosomal fraction is lower $(n=7 ; p<0.001)$, but the levels of activated $56 \mathrm{~K} 1$ are higher $(n=7 ; p<0.05)$ compared with the total fraction. C, S6K1 activation is increased in the synaptoneurosomal fraction of the insular cortex within 15 min but not 180 min of novel taste learning $(n=5, p<0.03 ; n=10, n$.s.). Cumulative data are shown in the graph and representative immunoblots of total and phospho-S6K1 are shown in the inset.

whereas at the second one, no difference was observed $\left(t_{(18)}=\right.$ 0.8 , n.s.) (Fig. $2 C$ ).

Rapamycin affects the phosphorylation and protein levels of different $\mathrm{mTOR}$ substrates in the GC in vivo

We examined the abundance and phosphorylation levels of several translation regulators, known to be substrates of mTOR. Specifically, we analyzed protein levels of eEF2, eEF1A, S6K1, and ERK2, and the phosphorylation levels of eEF2, S6K1, and ERK2, at two time points (15 and $45 \mathrm{~min}$ ) after the microinfusion of rapamycin $(10 \mu \mathrm{M})$ to the $\mathrm{GC}$ of naive rats.

At $15 \mathrm{~min}$, no modulation was observed. However, $45 \mathrm{~min}$ after the injection, the phosphorylation and total levels of several mTOR substrates were modulated.

The phosphorylation level of $66 \mathrm{~K} 1$ was significantly decreased (paired $t$ test, $t_{(4)}=4.7 ; p<0.01$ ) (Fig. $3 A$ ), indicating a decreased initiation rate. As for the elongation phase, increased levels of eEF2 phosphorylation together with decreased levels of
A

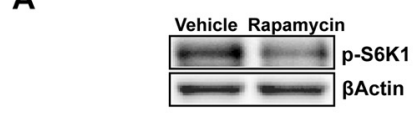

B
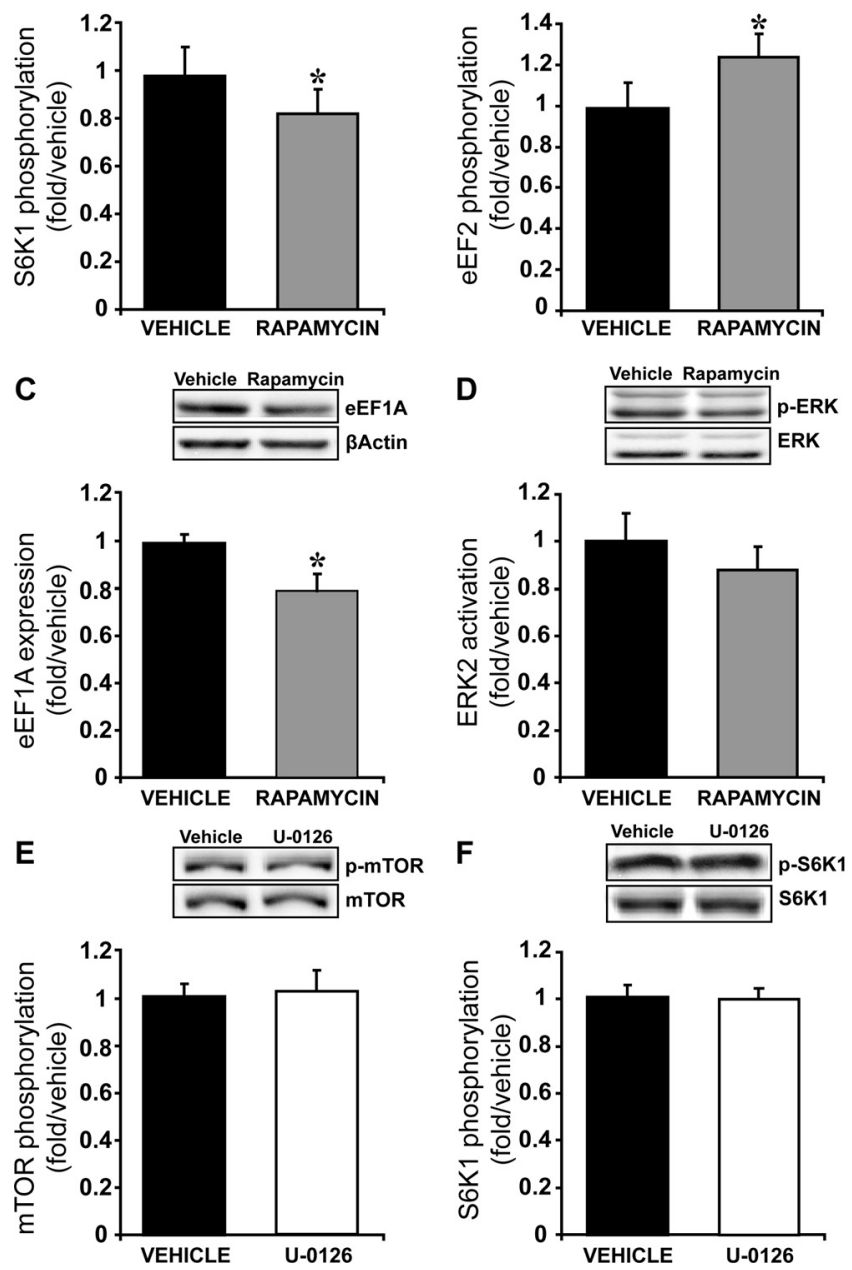

Figure 3. Biochemical effects 45 min after rapamycin microinfusion into $\mathrm{GC}$ of naive rats. $\mathrm{A}$ protein phosphorylation/expression is expressed as the ratio between rapamycin or U-0126 and vehicle values. $\boldsymbol{A}$, The phosphorylation levels of $\$ 6 \mathrm{~K} 1$ in brains of rapamycin-treated rats are significantly decreased $(n=5 ; p<0.01)$. $\boldsymbol{B}$, Increased levels of eEF2 phosphorylation are observed after rapamycin injection $(n=5 ; p<0.05)$. $C$, The total levels of eEF1A are reduced in rapamycin-injected rats $(n=5 ; p<0.05)$. $\boldsymbol{D}$, ERK2 phosphorylation is not modified after rapamycin application ( $n=5$; n.s.). $\boldsymbol{E}$, mTOR phosphorylation is not affected by U-0126 application ( $n=5 ;$ n.s.). $\boldsymbol{F}, \mathrm{U}-0126$ injection did not change the phosphorylation levels of S6K1 ( $n=$ $5 ;$ n.s.). Top panels at each point depict representative immunoblots from the gustatory cortex.

total eEF1A were observed (paired $t$ test, $t_{(4)}=-2.9 ; p<0.05$ and $t_{(4)}=2.9 ; p<0.05$, respectively) (Fig. $3 B, C$ ), both suggesting that rapamycin inhibits the elongation rate of protein synthesis.

Because it was previously shown that protein synthesis might be regulated in ERK-dependent manner (Kelleher et al., 2004) and that mTOR and ERK do crosstalk (Tsokas et al., 2007), we also analyzed the effect of mTOR inhibition on ERK2 phosphorylation and vice versa: the effect of ERK2 inhibition on mTOR and S6K1 phosphorylation. No effect was observed: the phosphorylation levels of ERK2 did not change after rapamycin application (paired $t$ test, $t_{(4)}=1.5$, n.s.) (Fig. $3 D$ ). Similarly, MEK inhibitor U-0126, injected into the gustatory cortex, did not affect the phosphorylation of either S6K1 (paired $t$ test, $t_{(4)}=0.1$, n.s.) (Fig. $3 E$ ) or mTOR (paired $t$ test, $t_{(4)}=-0.3$, n.s.) (Fig. $3 F$ ). 
Rapamycin microinjected into the GC impairs long-term taste memory

After the biochemical results, the next set of experiments was designed to test the requirement for mTOR activity in the GC for the consolidation of novel taste learning. To isolate the effect of novel taste per se from the confounding effect of the association between the novel taste and the malaise, we used the combination of CTA and latent inhibition paradigms. Typically, both the CTA and LI rats show significantly higher aversion indexes compared with controls, but LI rats are less aversive to saccharin than CTA rats (Rosenblum et al., 1993) (ANOVA, $F_{(2,29)}$ $=81.9 ; p<0.001$ ) (Fig. $4 A$ ). These results point out that single exposure to saccharin at the pre-exposure stage of LI suffices to produce long-term taste memory trace. In these experiments, we took into account two different temporal constrains. The first one is the time window at which we observed clear biochemical effect for rapamycin microinjection (i.e., $45 \mathrm{~min}$ ). The second one is the two waves of mTOR and S6K1 correlative phosphorylation after novel taste learning. To test if both time points of mTOR correlative phosphorylation are necessary for novel taste learning, rapamycin $(10 \mu \mathrm{M})$ was injected either $25 \mathrm{~min}$ before (before the short-time activation of mTOR) or $100 \mathrm{~min}$ after (before the second-wave activation of mTOR) the preexposure to saccharin.

Animals that were injected with rapamycin 25 min before taste learning show significantly higher aversion rates for saccharin compared with vehicle-injected rats (repeated-measure ANOVA, $F_{(1,10)}=8.46 ; p<0.02$ ) (Fig. $4 C$ ). The application of rapamycin during learning did not affect the rate of the extinction when comparing between the two groups on three consecutive test days.

Next, we examined the effectiveness of rapamycin when applied $100 \mathrm{~min}$ after the pre-exposure to novel taste. Again, animals injected with rapamycin exhibit higher aversion index than vehicle injected rats, going up to the values obtained in CTA group (repeated-measures ANOVA, $F_{(2,16)}=7.351 ; p<0.01$ ) (Fig. $4 D$ ). Together, the results demonstrate that the activity of mTOR in the GC is necessary for taste memory formation both during learning and $2-3 \mathrm{~h}$ after memory acquisition. A similar time course was observed using the more general protein synthesis inhibitor, anisomycin (Merhav and Rosenblum, 2008). A representative slice with Nissle staining shows the position of the cannulae and the injection site (Fig. 4B).

\section{mTOR inhibition reduces the expression of PSD-95 in the cortex in vivo}

The results thus far demonstrate that local rapamycin microinjection attenuates learning and modulates the translation machinery in the cortex in vivo. We wanted to further measure the effect of rapamycin cortical administration on specific synaptic protein expression. We thus measured the expression of dendritic scaffolding protein PSD-95, a protein known to be crucial for synaptic stability (Migaud et al., 1998), its expression is known to be dependent on the mTOR pathway (Akama and
McEwen, 2003; Lee et al., 2005), and recently was found to be induced after taste learning in the GC (Elkobi et al., 2008).

First, we assessed the effect of insulin on mTOR activation and PSD-95 expression in hippocampal slices. Ten minutes after insulin application, mTOR phosphorylation increased by $40 \%(t$ test, $t_{(10)}=-3.2 ; p<0.02$ ) (Fig. $5 A$ ). We then tested whether insulin application to hippocampal slices modulate PSD-95 expression. Consistent with findings of Lee et al. (2005), PSD-95 expression was significantly increased after insulin treatment $(t$ test, $t_{(10)}=-3 ; p<0.02$ ) (Fig. $5 B$ ). After the results in the slice preparation, we evaluated the expression of PSD-95, 15 and 45 min after local rapamycin application to the GC in vivo. While shortly after rapamycin application, PSD-95 expression was not affected ( $t$ test, $t_{(6)}=-0.7$, n.s.), 45 min later (the time point when rapamycin modulated the translation machinery) (Fig. 3) the levels of PSD-95 were significantly reduced $\left(t\right.$ test, $t_{(4)}=4.1$; $p<0.02$ ) (Fig. $5 C$ ). Similar results were obtained using a more general protein synthesis inhibitor, anisomycin (Elkobi et al., 2008).

\section{Discussion}

The role of translational regulation in synaptic plasticity and memory consolidation is now under extensive investigation (Kelleher et al., 2004; Belelovsky et al., 2005; Banko et al., 2007; Costa-Mattioli et al., 2007). Translation can be modulated and controlled by mTOR, which regulates the synthesis of members of translation machinery. The specific mTOR inhibitor, rapamycin, selectively inhibits the translation of mRNAs encoding ribosomal proteins and elongation factors (Terada et al., 1994). Recent studies demonstrate that mTOR signaling plays a role in neuronal plasticity (Casadio et al., 1999; Tang et al., 2002; Cammalleri et al., 2003; Horwood et al., 2006; Tsokas et al., 2007), and specifically a critical role in control of synaptic activity-induced protein synthesis (such as $\alpha$-CaMKII and MAP2) in hippocampal neurons (Gong et al., 2006). Furthermore, mTOR signaling was shown to be highly involved in the process of learning and memory (Tischmeyer et al., 2003; Dash et al., 2006; Parsons et al., 2006; Bekinschtein et al., 2007) and in brain dysfunction in humans 
A
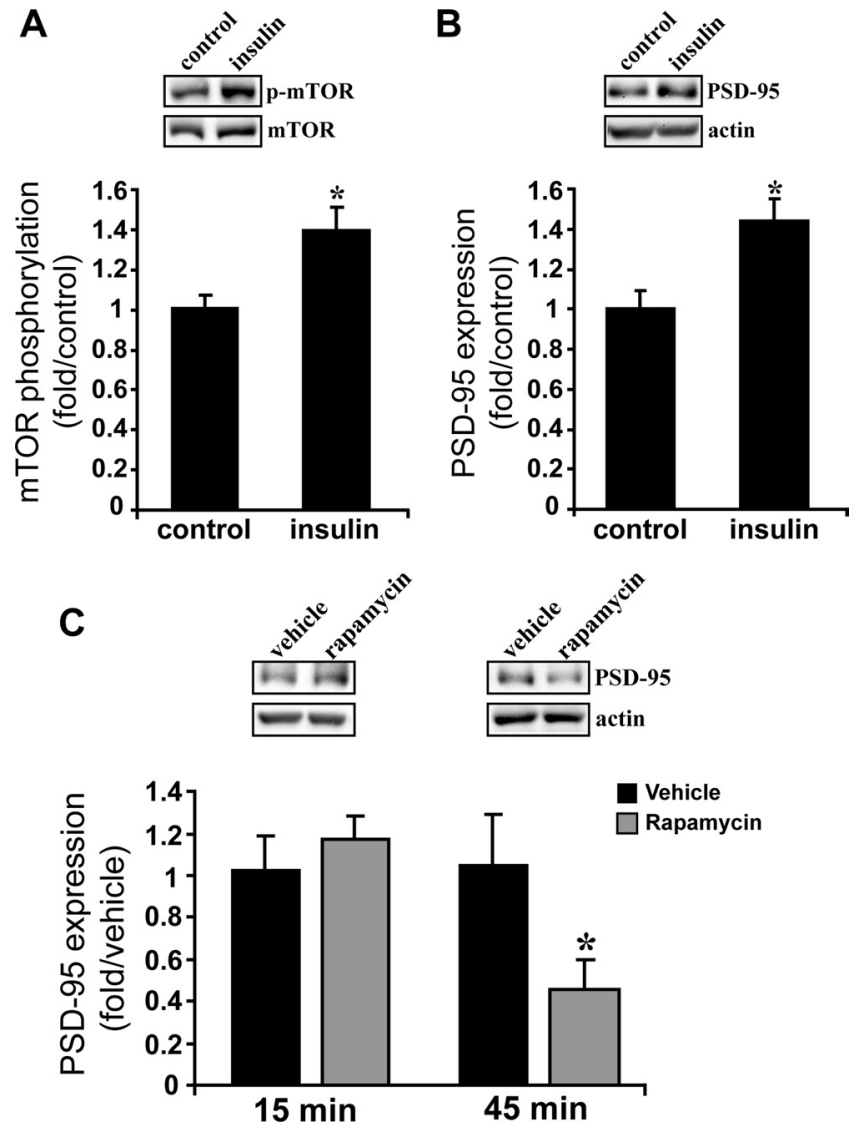

Figure 5. PSD-95 expression is mTOR dependent. $\boldsymbol{A}, \boldsymbol{B}$, Hippocampal slices were either not treated (control) or treated with $1.5 \mu \mathrm{m}$ insulin. $\boldsymbol{A}$, Insulin activates the mTOR. The graph presents cumulative data $(n=5 ; p<0.02)$. The top panel depicts representative immunoblots of phospho-mTOR and total mTOR. $\boldsymbol{B}$, Insulin treatment upregulates the expression of PSD-95. The graph represents cumulative data $(n=5 ; p<0.02)$. The top panel depicts representative immunoblots of PSD-95 and actin. C, The expression of PSD-95 in vivo is mTOR dependent. Within 45 min of local rapamycin application to the GC, the levels of PSD-95 are significantly reduced $(n=5 ; p<0.02)$.

(Lafay-Chebassier et al., 2005; Paccalin et al., 2006a,b). Based on these data, we studied the role of the mTOR pathway as a specific translation regulator in the cortex after acquiring novel sensory information.

Interestingly, mTOR signaling in the gustatory cortex is required for the formation of long-term memory of novel taste in rats. Compared with control rats, local cortical application of rapamycin, both before and after pre-exposure to novel taste, results in attenuated memory. Only four previous studies have established the necessity of mTOR activation for intact learning and memory processes. Local rapamycin application to the amygdala has attenuated the formation of fear memory (Parsons et al., 2006). As for hippocampal-dependent learning, the formation of both long-term fear memory and long-term spatial memory was found to require mTOR activation (Dash et al., 2006; Bekinschtein et al., 2007). Finally, in cortical-dependent learning in gerbils, the activation of rapamycin-sensitive signaling was shown to be necessary for long-term consolidation of auditory memory (Tischmeyer et al., 2003).

One of the intriguing aspects of such an effect of rapamycin on the different types of learning is the fact that contrary to the effect of a general protein synthesis inhibitor such as anisomycin, rapamycin inhibits only a small population of mRNAs. Several studies demonstrated that rapamycin treatment results in small changes in overall protein synthesis rates (Jefferies et al., 1997; Parsons et al., 2006). This means that the blockade of the mTOR pathway with rapamycin prevents the translation of a distinct subset of relevant transcripts rather than a global blockade of protein synthesis. mTOR inhibition is believed to target mRNAs which have extensive secondary structure and/or oligopyrimidine tracts in the $5^{\prime}$ region (Raught et al., 2001). The observation that the inhibition of only a small subpopulation of mRNAs can result in such a behavioral outcome suggests a critical role of mTOR targets in the process of long-term memory consolidation.

To further assess the role of mTOR in cortical-dependent learning, we analyzed whether the activation of mTOR pathway correlates with novel taste learning. The biochemical analysis revealed a biphasic activation of mTOR, $15 \mathrm{~min}$ and $3 \mathrm{~h}$ after novel taste learning in the gustatory cortex. These results are strengthened by our findings that the phosphorylation of S6K1, a direct mTOR target, is also increased in a similar temporal pattern, and there is a correlation between the two. Moreover, behavioral analysis of S6K1 knock-out mice revealed clear attenuation of taste memory, providing another genetic indication for the importance of the mTOR pathway in molecular mechanisms of taste learning (Antion et al., 2008).

Another important point deals with the observed biphasic effect of mTOR activation. A number of studies have reported two-wave activation of several proteins after learning tasks. The phosphorylation of the transcription factor cAMP response element-binding protein and ERK showed a biphasic time course in fear-conditioning tasks and stress situations, with an early peak corresponding to what we observed, and a second rise of several hours (2-9 h) post-training (Bilang-Bleuel et al., 2002; Trifilieff et al., 2006). Similarly, the expression of an immediate-early gene $\arg 3.1 /$ arc mRNA was increased in a biphasic manner, 15 min and $4.5 \mathrm{~h}$ after training in one-trial avoidance learning in mice (Montag-Sallaz et al., 1999). This finding is of specific interest, as arc was found to be expressed dendritically in a rapamycinsensitive manner (Takei et al., 2001). The biphasic effect reported above and in our study corresponds temporally to the two mRNA and protein synthesis-dependent periods of long-term memory formation (Bekinschtein et al., 2007). Nonetheless, in addition to the biphasic activation, we found that mTOR pathway activation is differential at the two time points, localizing mainly to the synapse during the first wave, and showing total cellular distribution during the later one.

To confirm the biochemical effect of rapamycin, we analyzed both total and phosphorylation states of several translation regulators. Some of these proteins are well established mTOR substrates, whereas others are believed to be indirect targets of mTOR. Our observation of decreased phospho-levels of S6K1 after rapamycin administration suggests attenuated initiation rate, whereas downregulation of eEF1A and increased phosphoeEF2 levels indicate decreased elongation. Interestingly, eEF2 is phosphorylated after novel taste learning (Belelovsky et al., 2005), suggesting that two opposite signaling are working together in the cortex during memory consolidation. This spatiotemporal relationship between protein synthesis initiation and elongation may enable the localized expression of specific subset of proteins necessary for the consolidation process (Belelovsky et al., 2005).

Next, we addressed how PSD-95 expression relates to mTORdependent translation control. Surprisingly, the inhibition of mTOR pathway by rapamycin application resulted in a rapid and dramatic decrease in PSD-95 levels. Indeed, the ability of fast synthesis/degradation of PSD-95 was shown to occur in response 
to several stimulations. Estrogen stimulation lead to a rapid increase in PSD-95 new protein synthesis in vitro (Akama and McEwen, 2003). As for the rate of PSD-95 degradation, treatment of cultured cortical neurons with soluble oligomer of $\beta$-amyloid resulted in dramatic downregulation of PSD-95 within $60 \mathrm{~min}$ (Roselli et al., 2005). Furthermore, in response to NMDA receptor activation, PSD-95 is rapidly removed from the synaptic sites by proteasome-dependent degradation (Colledge et al., 2003). In a study examining the turnover rate of different synaptic proteins, a robust ongoing turnover of total PSD proteins, including the PSD-95, occurred within only a few hours, suggesting a high turnover rate of these proteins (Ehlers, 2003). Finally, PSD-95 induction was found to be both correlated with and necessary for taste memory consolidation, and anisomycin, a general protein synthesis inhibitor, had similar effect to that of rapamycin (Elkobi et al., 2008).

As for the exact relationship between mTOR activity and PSD-95 levels, it is not yet clear. Rapamycin treatment of NG108-15 neurons reduced estrogen-stimulated PSD-95 protein synthesis to less than control levels (Akama and McEwen, 2003). A more recent study demonstrated that insulin-induced increase in the PSD-95 protein expression in the rat hippocampal slices is inhibited by rapamycin (Lee et al., 2005). Importantly, both studies present evidence that the phosphatidylinositol 3-kinase (PI3K) inhibitor LY294002 causes a similar effect on PSD-95 expression. Together, these data suggest that the activation of PI3K-mTOR signaling pathway is essential for both insulin- and estrogen-induced upregulation of PSD-95. Our results concerning the effect of rapamycin on PSD-95 provide first evidence for such a relationship between mTOR signaling and PSD-95 expression in vivo.

The involvement of the mTOR pathway in learning and memory processes may have clinical implications. One of the diseases strongly characterized with memory disturbances is Alzheimer's disease (AD). Several recent studies investigated the role of mTOR signaling in $\mathrm{AD}$. The lymphocytes of $\mathrm{AD}$ patients were found to be marked by a significant decrease of phosphorylated S6K1 and mTOR. Furthermore, the decrease in both kinases correlates with decline of memory and cognition (Lafay-Chebassier et al., 2005; Paccalin et al., 2006a,b). Similar effects were obtained in a study using cellular and transgenic models of $\mathrm{AD}$. In a cellular imitation of $\mathrm{AD}$, a rapid and persistent downregulation of mTOR-S6K1 phosphorylation was observed (Lafay-Chebassier et al., 2005). Moreover, phosphorylated forms of mTOR and S6K1 were decreased in the cortex of transgenic AD model. However, there is still no agreement as for the direction of change in mTOR phosphorylation. Another study demonstrated increased levels of phospho-mTOR in AD brains, positively correlated with total tau and p-tau (Li et al., 2005). Because tau proteins compose the neurofibrillary tangles, one of the major neuropathological hallmarks in $\mathrm{AD}$, these data suggest that $\mathrm{AD}$ patients exhibit apparent abnormalities of translation control-related elements.

To summarize, we demonstrate that mTOR signaling is both correlative with and necessary for cortical-dependent learning in rats. Further studies are required to investigate the role of specific proteins that are regulated by the mTOR pathway in the cortex in vivo during learning to enable memory consolidation.

\section{References}

Akama KT, McEwen BS (2003) Estrogen stimulates postsynaptic density-95 rapid protein synthesis via the $\mathrm{Akt} /$ protein kinase B pathway. J Neurosci 23:2333-2339.

Antion MD, Merhav M, Hoeffer CA, Reis G, Kozma SC, Thomas G, Schuman
EM, Rosenblum K, Klann E (2008) Removal of S6K1 and S6K2 leads to divergent alterations in learning, memory, and synaptic plasticity. Learn Mem 15:29-38.

Banko JL, Merhav M, Stern E, Sonenberg N, Rosenblum K, Klann E (2007) Behavioral alterations in mice lacking the translation repressor 4E-BP2. Neurobiol Learn Mem 87:248-256.

Bekinschtein P, Katche C, Slipczuk LN, Igaz LM, Cammarota M, Izquierdo I, Medina JH (2007) mTOR signaling in the hippocampus is necessary for memory formation. Neurobiol Learn Mem 87:303-307.

Belelovsky K, Elkobi A, Kaphzan H, Nairn AC, Rosenblum K (2005) A molecular switch for translational control in taste memory consolidation. Eur J Neurosci 22:2560-2568.

Berman DE, Hazvi S, Rosenblum K, Seger R, Dudai Y (1998) Specific and differential activation of mitogen-activated protein kinase cascades by unfamiliar taste in the insular cortex of the behaving rat. J Neurosci 18:10037-10044.

Bilang-Bleuel A, Rech J, De Carli S, Holsboer F, Reul JM (2002) Forced swimming evokes a biphasic response in CREB phosphorylation in extrahypothalamic limbic and neocortical brain structures in the rat. Eur J Neurosci 15:1048-1060.

Bures BRF, Yamamoto T (1998) Conditioned taste aversion. Memory of a special kind. Oxford: Oxford UP.

Cammalleri M, Lütjens R, Berton F, King AR, Simpson C, Francesconi W, Sanna PP (2003) Time-restricted role for dendritic activation of the mTOR-p70S6K pathway in the induction of late-phase long-term potentiation in the CA1. Proc Natl Acad Sci U S A 100:14368-14373.

Casadio A, Martin KC, Giustetto M, Zhu H, Chen M, Bartsch D, Bailey CH, Kandel ER (1999) A transient, neuron-wide form of CREB-mediated long-term facilitation can be stabilized at specific synapses by local protein synthesis. Cell 99:221-237.

Colledge M, Snyder EM, Crozier RA, Soderling JA, Jin Y, Langeberg LK, Lu H, Bear MF, Scott JD (2003) Ubiquitination regulates PSD-95 degradation and AMPA receptor surface expression. Neuron 40:595-607.

Costa-Mattioli M, Gobert D, Stern E, Gamache K, Colina R, Cuello C, Sossin W, Kaufman R, Pelletier J, Rosenblum K, Krnjeviæ K, Lacaille JC, Nader K, Sonenberg N (2007) eIF2alpha phosphorylation bidirectionally regulates the switch from short- to long-term synaptic plasticity and memory. Cell 129:195-206.

Dash PK, Orsi SA, Moore AN (2006) Spatial memory formation and memory-enhancing effect of glucose involves activation of the tuberous sclerosis complex-mammalian target of rapamycin pathway. J Neurosci 26:8048-8056.

Ehlers MD (2003) Activity level controls postsynaptic composition and signaling via the ubiquitin-proteasome system. Nat Neurosci 6:231-242.

Ehrlich I, Klein M, Rumpel S, Malinow R (2007) PSD-95 is required for activity-driven synapse stabilization. Proc Natl Acad Sci U S A 104:4176-4181.

Elkobi A, Ehrlich I, Belelovsky K, Barki-Harrington L, Rosenblum K (2008) ERK-dependent PSD-95 induction in the gustatory cortex is necessary for taste learning, but not retrieval. Nat Neurosci 11:1149-1151.

Gong R, Park CS, Abbassi NR, Tang SJ (2006) Roles of glutamate receptors and the mammalian target of rapamycin (mTOR) signaling pathway in activity-dependent dendritic protein synthesis in hippocampal neurons. J Biol Chem 281:18802-18815.

Hay N, Sonenberg N (2004) Upstream and downstream of mTOR. Genes Dev 18:1926-1945.

Hebb DO (1949) The organization of behavior. New York: Wiley.

Horwood JM, Dufour F, Laroche S, Davis S (2006) Signalling mechanisms mediated by the phosphoinositide 3-kinase/Akt cascade in synaptic plasticity and memory in the rat. Eur J Neurosci 23:3375-3384.

Jefferies HB, Fumagalli S, Dennis PB, Reinhard C, Pearson RB, Thomas G (1997) Rapamycin suppresses 5'TOP mRNA translation through inhibition of p70s6k. ЕMBO J 16:3693-3704.

Kelleher RJ 3rd, Govindarajan A, Jung HY, Kang H, Tonegawa S (2004) Translational control by MAPK signaling in long-term synaptic plasticity and memory. Cell 116:467-479.

Lafay-Chebassier C, Paccalin M, Page G, Barc-Pain S, Perault-Pochat MC, Gil R, Pradier L, Hugon J (2005) mTOR/p70S6k signalling alteration by Abeta exposure as well as in APP-PS1 transgenic models and in patients with Alzheimer's disease. J Neurochem 94:215-225.

Lee CC, Huang CC, Wu MY, Hsu KS (2005) Insulin stimulates postsynaptic density-95 protein translation via the phosphoinositide 3-kinase-Akt- 
mammalian target of rapamycin signaling pathway. J Biol Chem 280:18543-18550.

Li X, Alafuzoff I, Soininen H, Winblad B, Pei JJ (2005) Levels of mTOR and its downstream targets $4 \mathrm{E}-\mathrm{BP} 1, \mathrm{eEF} 2$, and eEF2 kinase in relationships with tau in Alzheimer's disease brain. FEBS J 272:4211-4220.

Loewith R, Jacinto E, Wullschleger S, Lorberg A, Crespo JL, Bonenfant D, Oppliger W, Jenoe P, Hall MN (2002) Two TOR complexes, only one of which is rapamycin sensitive, have distinct roles in cell growth control. Mol Cell 10:457-468.

Lubow RE (1989) Latent inhibition and conditioned attention theory. Cambridge, UK: Cambridge UP.

Meiri N, Rosenblum K (1998) Lateral ventricle injection of the protein synthesis inhibitor anisomycin impairs long-term memory in a spatial memory task. Brain Res 789:48-55.

Merhav M, Rosenblum K (2008) Facilitation of taste memory acquisition by experiencing previous novel taste is protein-synthesis dependent. Learn Mem 75:501-507.

Merhav M, Kuulmann-Vander S, Elkobi A, Jacobson-Pick S, Karni A, Rosenblum K (2006) Behavioral interference and C/EBPbeta expression in the insular-cortex reveal a prolonged time period for taste memory consolidation. Learn Mem 13:571-574.

Migaud M, Charlesworth P, Dempster M, Webster LC, Watabe AM, Makhinson M, He Y, Ramsay MF, Morris RG, Morrison JH, O'Dell TJ, Grant SG (1998) Enhanced long-term potentiation and impaired learning in mice with mutant postsynaptic density-95 protein. Nature 396:433-439.

Montag-Sallaz M, Welzl H, Kuhl D, Montag D, Schachner M (1999) Novelty-induced increased expression of immediate-early genes c-fos and arg 3.1 in the mouse brain. J Neurobiol 38:234-246.

Paccalin M, Pain-Barc S, Pluchon C, Paul C, Besson MN, Carret-Rebillat AS, Rioux-Bilan A, Gil R, Hugon J (2006a) Activated mTOR and PKR kinases in lymphocytes correlate with memory and cognitive decline in Alzheimer's disease. Dement Geriatr Cogn Disord 22:320-326.

Paccalin M, Al Khidir F, Barc SP, Pluchon C, Perrault-Pochat MC, Gil R, Hugon J (2006b) Peripheral p70S6k levels and emotional memory in patients with Alzheimer's disease. Neurosci Lett 410:162-164.

Parsons RG, Gafford GM, Helmstetter FJ (2006) Translational control via the mammalian target of rapamycin pathway is critical for the formation and stability of long-term fear memory in amygdala neurons. J Neurosci 26:12977-12983.

Paxinos G, Watson C (1986) The rat brain in stereotaxic coordinates, Ed 3. San Diego: Academic.

Quinlan EM, Olstein DH, Bear MF (1999) Bidirectional, experiencedependent regulation of N-methyl-D-aspartate receptor subunit compo- sition in the rat visual cortex during postnatal development. Proc Natl Acad Sci U S A 96:12876-12880.

Raught B, Gingras AC, Sonenberg N (2001) The target of rapamycin (TOR) proteins. Proc Natl Acad Sci U S A 98:7037-7044.

Roselli F, Tirard M, Lu J, Hutzler P, Lamberti P, Livrea P, Morabito M, Almeida OF (2005) Soluble beta-amyloid1-40 induces NMDAdependent degradation of postsynaptic density-95 at glutamatergic synapses. J Neurosci 25:11061-11070.

Rosenblum K (2008) Conditioned taste aversion and taste learning: molecular mechanisms. In: Learning and memory: a comprehensive reference, Chap 4.13 (Byrne J, ed), pp 217-234. Oxford: Elsevier.

Rosenblum K, Meiri N, Dudai Y (1993) Taste memory: the role of protein synthesis in gustatory cortex. Behav Neural Biol 59:49-56.

Rosenblum K, Berman DE, Hazvi S, Lamprecht R, Dudai Y (1997) NMDA receptor and the tyrosine phosphorylation of its $2 \mathrm{~B}$ subunit in taste learning in the rat insular cortex. J Neurosci 17:5129-5135.

Takei N, Kawamura M, Hara K, Yonezawa K, Nawa H (2001) Brain-derived neurotrophic factor enhances neuronal translation by activating multiple initiation processes: comparison with the effects of insulin. J Biol Chem 276:42818-42825.

Tang SJ, Reis G, Kang H, Gingras AC, Sonenberg N, Schuman EM (2002) A rapamycin-sensitive signaling pathway contributes to long-term synaptic plasticity in the hippocampus. Proc Natl Acad Sci U S A 99:467-472.

Terada N, Patel HR, Takase K, Kohno K, Nairn AC, Gelfand EW (1994) Rapamycin selectively inhibits translation of mRNAs encoding elongation factors and ribosomal proteins. Proc Natl Acad Sci U S A 91:11477-11481.

Tischmeyer W, Schicknick H, Kraus M, Seidenbecher CI, Staak S, Scheich H, Gundelfinger ED (2003) Rapamycin-sensitive signalling in long-term consolidation of auditory cortex-dependent memory. Eur J Neurosci 18:942-950.

Trifilieff P, Herry C, Vanhoutte P, Caboche J, Desmedt A, Riedel G, Mons N, Micheau J (2006) Foreground contextual fear memory consolidation requires two independent phases of hippocampal ERK/CREB activation. Learn Mem 13:349-358.

Tsokas P, Ma T, Iyengar R, Landau EM, Blitzer RD (2007) Mitogenactivated protein kinase upregulates the dendritic translation machinery in long-term potentiation by controlling the mammalian target of rapamycin pathway. J Neurosci 27:5885-5894.

Yefet K, Merhav M, Kuulmann-Vander S, Elkobi A, Belelovsky K, JacobsonPick S, Meiri N, Rosenblum K (2006) Different signal transduction cascades are activated simultaneously in the rat insular cortex and hippocampus following novel taste learning. Eur J Neurosci 24:1434-1442. 